\title{
A participação das mulheres na política institucionalizada do Distrito Federal: Um olhar sobre atuações e repercussões no turismo sustentável
}

Participation of women in politics institutionalized Federal District: A glimpse of interventions and impact on sustainable tourism

Neuza de Farias Araújo ${ }^{1}$ David Malheiros ${ }^{2}$

1 Doutora em Sociologia pela Université Paris VII. Professora no Programa de Pós-Graduação em Turismo da Universidade de Brasília. Pesquisadora de estudos sobre as mulheres, diversidade e interdisciplinaridade de gêneros. E-mail: nfariasaraujo@gmail.com

2 Bacharel em Serviço Social pela Universidade de Brasília. Atualmente, cursa pós-graduação em Université de Strasbourg - França. E-mail: david_malheiros@hotmail.com 


\section{Resumo}

O presente texto faz parte de nossas reflexões e investigações sobre a temática que envolve as mulheres na sociedade, e tem como objetivo analisar, à luz da teoria crítica, a participação política das mulheres no espaço institucional da Câmara Legislativa do Distrito Federal quanto à sua atuação como deputadas no que diz respeito aos projetos de lei apresentados. Como pano de fundo será feita uma breve análise das condições de opressão da mulher na sociedade. Nosso interesse é acadêmico e procuramos trazer para o debate as questões ligadas à contribuição feminina no contexto estudado. Utilizamos estudos de casos para identificar os projetos de cunho social e político em benefício da comunidade, relacionando os aspectos de melhoria da população com a noção de turismo sustentável.

Palavras-chave: Participação política. Mulheres. Gênero. Espaço institucional. Turismo sustentável.

\section{Abstract}

This text is part of our reflections and research on the topic involving women in society, and aims to analyze, the light of critical theory, political participation of women in the institutional space of the Legislative Chamber of the Federal District as to its role as MPs with regard to bills presented. The backdrop is a brief analysis of the conditions of oppression of women in society. Our interest is academic and seeks to bring the debate to issues related to women's contribution in the context studied. We use case studies to identify projects of social and political benefit of the community, relating aspects of improvement of the population with the notion of sustainable tourism.

Keywords: Political participation. Women. Gender. Institutional area. Sustainable tourism.

\section{Introdução}

Parte de nossas reflexões e investigações sobre a temática que envolve as mulheres na sociedade, este artigo procura analisar, à luz da teoria crítica, a participação 
política das mulheres no espaço institucional da Câmara Legislativa do Distrito Federal quanto à sua atuação como deputadas no que diz respeito aos projetos de lei que apresentaram. Procederemos uma breve análise das condições de opressão da mulher na sociedade. Não citamos nomes e partidos visando resguardar suas identidades, uma vez que nosso interesse é acadêmico, procurando trazer para o debate as questões ligadas à contribuição feminina no contexto estudado. Utilizamos nos estudos de casos letras para identificar as mulheres deputadas, e números para os partidos os quais elas estão inseridas.

\section{Referências históricas sobre a opressão das mulheres no capitalismo}

Discutir a questão da mulher e de como se dá sua participação nas esferas de poder passa necessariamente por uma reflexão acerca do papel que é historicamente atribuído às mulheres no sistema capitalista.

O capitalismo como sistema econômico se assenta na propriedade privada dos meios de produção para a exploração do trabalho assalariado e para tal fim utiliza-se também de distinções entre os tipos de trabalhadores, por exemplo, homens e mulheres. Friedrich Engels define muito bem como se deu historicamente e no que consiste o papel da mulher na sociedade dividida pelo advento da propriedade privada dos meios de produção. É na esteira dessa discussão que diz Engels (1987) sobre o papel mulher na sociedade de classes e a origem histórica dessa opressão:

"A primeira divisão do trabalho é a que se fez entre o homem e a mulher para a procriação dos filhos" (Engels, 1987, p.70 e 71). Hoje, podemos acrescentar: o primeiro antagonismo de classes que apareceu na história coincide com o desenvolvimento do antagonismo entre o homem e a mulher na monogamia; e a primeira opressão de classes, com a opressão do sexo feminino pelo masculino. A monogamia foi um grande progresso histórico, mas ao mesmo tempo, iniciou, juntamente com a escravidão e as riquezas privadas, aquele período, que dura até nossos dias, no qual cada progresso é simultaneamente um retrocesso relativo.

Assim, a mulher é relegada ao papel de reprodutora da força de trabalho, ao âmbito doméstico, confinada ao espaço das relações familiares e afetivas. Ao homem, em contrapartida, o trabalho e a organização da produção, a propriedade. Nesse movimento que segrega homem e mulher e sob o qual se assenta a exploração do trabalho que é a raiz das desigualdades humanas, se mantém historicamente, com avanços e retrocessos, a opressão do homem sob a mulher, o machismo.

E ainda com a introdução do sufrágio feminino, no mundo sendo introduzido pri- 
meiramente pela Nova Zelândia, em 1893, e, no Brasil, em 1932, a participação política das mulheres permaneceu discreta em toda a história, sendo o peso das relações da opressão machista de difícil superação. É evidente que durante o século XX há um nítido aumento da participação política feminina, bem como da melhoria dos salários em relação aos homens e da diminuição do preconceito, mas mesmo assim foram transformações que não modificaram de fato as relações machistas que inviabilizavam a participação das mulheres na política. É quando se evoca a necessidade de uma reflexão para além da questão da opressão machista, dentro de uma perspectiva na qual a desigualdade está intimamente ligada à opressão machista que, por conseguinte explica-se pelas relações introduzidas no âmbito da propriedade privada que conduzem à opressão da mulher pelo homem. E nesse sentido, esclarece Imamoto (2008), falando sobre a questão social e sua dimensão de classe,

A "questão social" é indissociável da sociabilidade capitalista fundada na exploração do trabalho, que a reproduz ampliadamente. Ela envolve uma arena de lutas políticas e culturais contra as desigualdades socialmente produzidas. Suas expressões condensam múltiplas desigualdades, mediadas por disparidades nas relações de gênero, características étnico-raciais e formações regionais, colocando em causa amplos segmentos da sociedade civil no acesso aos bens da civilização. Dispondo de uma dimensão estrutural - enraizada na produção social contraposta à apropriação privada do trabalho - "a questão social" atinge visceralmente a vida dos sujeitos numa luta aberta e surda pela cidadania (IANNI, 1992), no embate pelo respeito aos direitos civis, sociais e políticos e aos direitos humanos. Esse processo é denso de conformismos e rebeldias, expressando a consciência e luta que acumule forças para o reconhecimento das necessidades de cada um e de todos os indivíduos sociais.

Portanto, discutir a questão da mulher na sociedade capitalista e da sua participação política deve ter como elemento fundamental a relação íntima que há entre a desigualdade produzida pelo capitalismo e os preconceitos que este produz. $\mathrm{E}$ assim, a participação política das mulheres depende de um enfrentamento claro da opressão machista na sociedade e da própria desigualdade social. Por fim, a participação da mulher na esfera da política que, como veremos, ainda é discreta no Distrito Federal, depende da superação das relações de opressão da mulher pelo homem, dimensionando-se sempre a questão social como elemento que perpassa a vida social.

\section{A participação política das mulheres no Brasil: Breve histórico}

O histórico da participação política das mulheres no Brasil é bastante recente e 
remonta ao século XIV. Em 1827, é estendido também às mulheres o direito a frequentar a escola e, em 1879, as instituições de ensino superior. Em 1887, forma-se em São Paulo a primeira médica e, apenas em 1933, já século XX, é eleita a primeira mulher para o cargo de deputada. Somente em 1979 assume a primeira mulher senadora, por vacância do cargo.

A luta política das mulheres se deu sempre em um ambiente desfavorável, marcado pela opressão machista e pelas relações históricas de desigualdade que sempre caracterizaram a sociedade brasileira de uma maneira geral. Também é de se levar em conta que ao longo de sua história, o País atravessou longos processos ditatoriais que inviabilizaram o crescimento da luta das mulheres. Não é à toa, assim, que a primeira senadora tenha assumido apenas em 1979, cem anos após a autorização de ingresso nas instituições superiores e 46 anos após a eleição da primeira mulher para o cargo de deputada!

A participação política tem sido tarefa bastante árdua a ser conquistada pelas muIheres, de modo que ainda hoje se tem uma baixa participação nas esferas do poder federal e estadual. No âmbito dos sindicatos, a situação não é muito diferente, sendo que historicamente as lideranças sempre foram ocupadas por homens e só recentemente esse quadro tem se alterado. Dessa maneira, é possível concluir que a participação política das mulheres de fato aumentou, mas ainda é pequena se comparada à dos homens, o que demonstra a necessidade da superação da opressão machista bem como das relações de desigualdade que permeiam a própria política brasileira.

\section{A participação política no Distrito Federal}

Ao se falar de participação política no Distrito Federal (DF) é importante que se tenha em mente a história de seu nascimento. O DF foi criado em 1960 e até o ano de 1986 os seus habitantes não elegiam seus deputados e senadores, tampouco havia uma Câmara Legislativa. É fundamental que se tenha em conta que de 1964 a 1985 o Brasil se viu imerso em um período de repressão e autoritarismo levado a cabo pelos governos militares que se apossaram do poder mediante um golpe de Estado. Tal processo inviabilizou a existência de qualquer tipo de democracia no País e não foi diferente no DF.

Após mais de vinte anos de ditadura militar, os habitantes do DF puderam em 1986 eleger seus deputados e senadores. Passados quatro anos, foi eleito o primeiro governador e os deputados distritais. A Câmara Legislativa passou a ocupar o papel de reunir os representantes do DF, estando dividida em 24 deputados que legislam sobre temas relativos ao DF. A lei maior, a Lei Orgânica foi instituída em 
1993 e desde então a Câmara funciona realizando eleições periódicas no mesmo calendário das eleições nacionais, ou seja, de quatro em quatro anos.

Saber se a redemocratização significou de fato maior participação política pela via institucional é ainda muito complicado. É fato que a volta à democracia possibilitou a participação política na figura da Câmara Legislativa e a consequente possibilidade de se eleger representantes regionais. Também o debate político se fortaleceu, ampliando-se a participação que não pela via institucional. Foram vários os partidos e movimentos que surgiram nesse período.

\section{A participação política das mulheres no DF: A Câmara Legislativa}

A participação política das mulheres no âmbito do poder institucional, especificamente o espaço da Câmara Legislativa do DF se inicia com a criação da própria casa e suas primeiras eleições em 1990. Para a legislatura que se iniciaria em 1991 foram eleitas três deputadas. A segunda legislatura, que se iniciou em 1995 e foi até 1998 teve duas deputadas. Com relação à terceira legislatura, que foi do ano de 1999 a 2002, quatro deputadas foram eleitas. A quarta legislatura, de 2003 a 2006, apresentou um aumento, chegando a cinco deputadas. Durante a quinta legislatura, à qual compreende o ano de 2007 a 2010, houve uma queda para três deputadas. $\mathrm{Na}$ atual legislatura, a sexta, que começou em 2011 e irá até o ano de 2014, retornou-se ao número de cinco deputadas.

O quadro aponta para uma baixa participação das mulheres no espaço da Câmara Legislativa, sendo que durante sua breve história o número de deputadas não variou muito. A porcentagem de deputadas oscilou sempre de $12 \%$ a $20 \%$, quando o número de deputadas foi de cinco. É um número bastante discreto se temos em conta que a Câmara é composta por 24 deputados, ou seja, de um universo de $100 \%$, nas legislaturas onde foram eleitas maior número de mulheres, a porcentagem não chegou sequer a $30 \%$ dos parlamentares. Durante a segunda legislatura, a porcentagem chegou a $8 \%$, com apenas duas deputadas eleitas para a casa. $\mathrm{Na}$ atual legislatura, a porcentagem é mais uma vez de $20 \%$, com cinco deputadas.

Há que se ter cuidado ao se analisar os dados, pois ainda que em algumas das legislaturas a porcentagem tenha chegado a $20 \%$ da Câmara, não se pode inferir daí que as deputadas conseguiram ter espaço para chegarem a ser de fato atuantes. As baixas porcentagens somam-se ao fato de que tais deputadas nem sempre representavam um projeto societário que prezasse pela luta contra a desigualdade. $\mathrm{Na}$ verdade, historicamente, e tal análise poderia ser feita a posteriori, as deputadas 
eleitas pertenceram, majoritariamente, aos partidos conservadores como o antigo PFL e o PDMB. É importante frisar também que a denominação conservadora corresponde ao que definem os autores clássicos da tradição marxista como Marx, Engels, além de autores como lamamoto e José Paulo Neto.

Aqui, o conservadorismo é tido como a expressão da manutenção das relações de desigualdade que caracteriza o Brasil. A esse constructo se contrapõe a tradição da teoria crítica que visa à superação desse Estado de desigualdade promovendo justiça social e equidade entre os indivíduos. E como na frase de lamamoto (2008), citada anteriormente, as desigualdades e opressões no capitalismo se confluem e constituem os sujeitos que são histórica e culturalmente erigidos e, portanto, também o é com a opressão do homem sob a mulher. Assim, mesmo que houvesse um aumento significativo do número de deputadas, o que definitivamente não ocorreu nos últimos anos, ainda haveria uma outra questão a se pensar: a opressão da mulher não se resolve sem a luta contra a desigualdade e mais além, contra todo tipo de opressão.

\section{A sexta legislatura (2011-2014): A atuação das deputadas e os pro- jetos de lei apresentados}

Para se compreender a dinâmica da questão da participação das deputadas no âmbito da Câmara é importante que se conheça um pouco mais sobre os projetos de lei que cada deputada propôs. Dessa maneira se poderá conhecer um pouco mais sobre como atuam essas deputadas e sobre o que versam seus projetos de leis, se dizem respeito ao enfrentamento da questão social, ou seja, da desigualdade, seja em questões econômicas, culturais ou de gênero. E para tanto serão mencionados aqueles que versarem sobre temas de interesse social, como mencionado anteriormente.

\section{Casos analisados}

\subsection{Primeiro caso}

A deputada A do partido (1), foi eleita para a atual legislatura, junto com outras quatro deputadas, e apresentou 34 projetos de lei em 2011. Entre seus projetos de lei que têm cunho social, estão: o que visa assegurar atendimento em tempo razoável ao usuário do Sistema Único de Saúde (SUS); o PL 82-2011, que dispõe sobre campanha de esclarecimento e respeito às mulheres paraplégicas ou tetraplégicas grávidas; e o PL 514 - 2011, que diz respeito à criação de atendimento especial a alunos com déficit de atenção e hiperatividade na rede pública de ensino. Os pro- 
jetos de lei apresentados pela deputada, em sua maioria, não apresentam matéria social, e quando ocorre estão na área da deficiência e da saúde da mulher.

\subsection{Segundo caso}

A deputada B do partido (1), foi eleita para a atual legislatura e apresentou 80 projetos de lei no ano de 2011. Entre os projetos de interesse social, estão o PL 467-2011, que versa sobre o tratamento de doenças raras no DF; o PL-431-2011, que reserva vagões no metrô para mulheres; e o PL-410-2011, que dispõe sobre a reserva de vagas para deficientes nas universidades públicas do Distrito Federal. Entre outros projetos de lei que apresentam interesse social, estão o PL-71, que estabelece prioridade para maiores de 60 anos, deficientes e portadores de doenças graves no pagamento de precatórios judiciais de natureza alimentícia; e o PL-642011, que versa sobre a licença maternidade especial para servidoras públicas mães de bebês prematuros.

\subsection{Terceiro caso}

A terceira das cinco deputadas eleitas é a de letra C (1), que, em 2011, apresentou 27 projetos de lei. Entre os projetos de lei de interesse social, estão o PL-438-2011, que reserva vagões especiais no metrô para gestantes, mulheres com crianças de colo, deficientes e maiores de 65 anos; e o PL-83-2011, que obriga envio à Câmara Legislativa de demonstrativos sociais com dados estatísticos relativos à mulher.

\subsection{Quarto caso}

Com relação aos projetos enviados pela deputada D (2), em 2011, estes formam um total 46 projetos. Estão entre os projetos de lei de cunho social, o PL-615-2011. que diz respeito à política de direitos humanos e assistência aos filhos de mulheres apenadas; o PL-404-2011, que versa sobre a criação do regime especial de atendimento à mulher vítima de agressão no sistema de saúde pública do DF; o PL-3772011, sobre a política de saúde mental para agentes penitenciários; e o PL-3242011, que trata do tema do passe livre estudantil.

\subsection{Quinto caso}

A deputada E (3) apresentou doze projetos de lei em 2011. Entre aqueles levantados, que apresentaram cunho social, estão o PL-613-2011, que dispõe sobre a 
política de promoção da saúde do trabalhador dos serviços de saúde públicos e privados; o PL-365-2011, que assegura aos professores do Distrito Federal a concessão de descontos para aquisição de materiais didáticos e livros de formação; e o PL-192-2011, que obriga o governo do Distrito Federal a fazer constar nos editais de licitação e contratos direitos à obrigatoriedade de reserva de $5 \%$ de vagas de emprego para mulheres nas obras públicas. Além desses projetos de lei, também estão o PL-168-2011, que determina aos órgãos da administração pública direta ou indireta, autarquias e iniciativa privada que respeitem e observem o nome social de travestis e transexuais; e o PL-164-2011, que diz respeito à gestão democrática do sistema de ensino público do Distrito Federal.

Entre as cinco deputadas que compõem o grupo de 24 deputados da presente legislatura, aquela que mais apresentou projetos de cunho social, ainda que tenha apresentado um menor número de projetos de lei, foi a deputada $\mathrm{E}$ (3). A deputada F (2) também apresentou vários projetos de lei de cunho social. As demais deputadas apresentaram alguns projetos de lei, mas em menor número. É importante frisar que tendo apresentado projetos de interesse social, a participação política deve se dar também por meio das organizações populares e dos sindicatos, não ficando restrito ao espaço institucional, que tem historicamente seus limites e impõe claros retrocessos ao avanço do enfrentamento da questão social e ao aumento real da participação política das mulheres.

\section{Um balanço da participação política das mulheres pela via institu- cional na figura da Câmara Legislativa do DF}

A história da Câmara Legislativa demonstra que há uma baixa participação das mulheres nos espaços de poder. $\mathrm{O}$ caso analisado das deputadas evidencia que no âmbito da Câmara, as mulheres sempre tiveram participação discreta em número, ainda que uma ou outra deputada possa haver conquistado para si protagonismo na casa. No que diz respeito aos projetos elaborados, é possível concluir que existem projetos de cunho social levados a cabo pelas deputadas, ainda que com propostas discutíveis quanto a um real enfrentamento da desigualdade e que, mesmo que existam, não são a maioria dos projetos.

Portanto, é possível dizer que a participação das mulheres na Câmara legislativa do DF, quanto à sua atuação como deputada, é ainda muito discreta, assim como o número de deputadas eleitas, que sempre variou dentro de uma margem mínima, ora aumentado timidamente, ora diminuindo drasticamente. E ainda que não se possa fazer nenhuma afirmação a priori sobre o porquê isso acontece, é possível 
mesmo assim afirmar que o fato se liga à condição de opressão da mulher na própria sociedade, além da própria história política conturbada do País, que faz muito pouco tempo retornou a uma vida democrática plena.

\section{Repercussões no cenário turístico: As mulheres neste contexto}

Considerando que os conhecimentos e a prática sobre turismo trazem inquietações sobre sua sustentabilidade local, a participação das comunidades, e do Estado e para que exista desenvolvimento sustentável é necessário que a população esteja bem. Por isso, se faz necessário aqui descrevermos alguns aspectos que envolvem as mulheres nesta problemática.

O desenvolvimento sustentável é aquele que atende às necessidades do presente sem comprometer a possibilidade de as gerações futuras atenderem a suas próprias necessidades. Ele contém dois conceitos-chave: 1- o conceito de "necessidades", sobretudo as necessidades essenciais dos pobres no mundo, que devem receber a máxima prioridade; 2 - a noção das limitações que o estágio da tecnologia e da organização social impõe ao meio ambiente, impedindo-o de atender às necessidades presentes e futuras ${ }^{3}$.

Alguns estudos nesta área afirmam que desenvolvimento sustentável significa obter crescimento econômico necessário, garantindo a preservação do meio ambiente e o desenvolvimento social para o presente e gerações futuras. Portanto, para que ocorra o desenvolvimento sustentável é necessário que haja uma harmonização entre o desenvolvimento econômico, a preservação do meio ambiente, a justiça social, acesso a serviços públicos de qualidade, melhoria da qualidade de vida e o uso racional dos recursos da natureza. De forma que a inserção social das mulheres enquanto sujeitos políticos de fato e de direito se inclui no contexto principalmente no que concerne à justiça social, e acesso aos serviços de qualidade e equidade de oportunidades.

O conceito de sustentabilidade deve ser entendido como princípio fundamental na reformulação do planejamento turístico nacional. Face à sua relevância como elemento orientador do modelo de desenvolvimento turístico desejado. As relações entre turismo e sustentabilidade devem ser abordadas por meio dos princípios que norteiam o entendimento dos seus distintos campos ${ }^{4}$.

Vale ressaltar a criação do Índice de Desenvolvimento Sustentável (IDS), desen-

3 www.economiabr.net

4 Conteúdo Fundamental Turismo e Sustentabilidade, Ministério do Turismo, 2007. 
volvido pelo Instituto Brasileiro de Geografia e Estatística (IBGE), em 2002, que tem como objetivo estabelecer comparações entre regiões do Brasil e com outros países, no tocante ao desenvolvimento sustentável. São utilizados dados econômicos, sociais, institucionais e ambientais. O último IDS, apresentado pelo IBGE, em 2012, mostrou avanços nos últimos anos no desenvolvimento sustentável no País. Porém, ainda há muito a fazer, uma vez que estamos muito atrás com relação ao que tem sido feito nos países mais desenvolvidos ${ }^{5}$.

Segundo a Organização Mundial do Turismo (OMT), o turismo sustentável deve ser aquele que salvaguarda o ambiente e os recursos naturais, garantindo o crescimento econômico da atividade, ou seja, capaz de satisfazer as necessidades das presentes e futuras gerações, portanto, o desenvolvimento turístico deve pautar por "economizar os recursos naturais raros e preciosos, principalmente a água e a energia, e que venham a evitar, na medida do possível a produção de dejetos, deve ser privilegiado e encorajado pelas autoridades públicas nacionais, regionais e locais" ${ }^{6}$.

O turismo sustentável procura buscar a compatibilização entre os anseios dos turistas e os das regiões receptoras, garantindo não somente a proteção do meio ambiente, mas também estimulando o desenvolvimento da atividade em consonância com a sociedade local envolvida. Desenvolver o turismo de forma sustentável implica ações que sejam socialmente justas, economicamente viáveis e ecologicamente corretas, isto é, que atendam as necessidades econômicas, sociais e ecológicas da sociedade, conforme destacado pela OMT, em seu artigo 3, do Código Mundial de Ética do Turismo. Todavia as mulheres estão incluídas neste processo enquanto sujeitos sociais políticos de direitos.

Segundo o relatório de Roteiros do Brasil", "a atividade turística deve democratizar-se e humanizar-se, devendo ser acessível a todos, pois deve ser entendida como um direito de todos. Os processos de desenvolvimento do turismo ancorados na sustentabilidade sociocultural representa uma ação eficaz para enfrentar situações de desigualdade e desequilíbrio econômico e regional, posto que facilitam as condições para que homens e mulheres possam incluir-se e integrar-se com equidade (igualdade na diferença).

O movimento pautado pela ideia de igualdade na diferença, grupos, comunidades, etnias e povos historicamente excluídos, assim como diferentes gerações, orientações sexuais, categorias de trabalhadores, pessoas com deficiência e com

5 IBGE, Indicadores de Desenvolvimento Sustentável, 2012.

6 Artigo 3, Código de Ética - OMT.

7 Ministério do Turismo, 2007. 
restrição de mobilidade, podem inserir-se na sociedade a partir do setor de serviços e, em particular, do setor de turismo, hospitalidade gastronomia, na condição de pequenos empresários, camponeses, artesãos trabalhadores e consumidores.

O relatório citado assinala que é importante entender que as mudanças históricas em processo no mundo atual têm como base movimentos de baixo para cima, do pequeno ao grande, do micro ao macro. Nesse cenário, países menos desenvolvidos podem tornar-se atores principais, e pobres e excluídos podem se transformar em protagonistas sociais. "De fato, em muitos países, o turismo tem significado avanços socioeconômicos, melhoria do padrão de vida e um enriquecimento tanto social quanto cultural, levando a uma percepção de prosperidade social e econômica."

No Brasil, em muitos casos, o incremento do fluxo turístico, gera, reforça ou intensifica as injustiças socioculturais preexistentes. Alguns poucos se beneficiam do patrimônio natural e cultural de todos, enquanto a maioria, especialmente a população receptiva, não se beneficia e vivencia um processo de exclusão social e espacial ${ }^{8}$.

\section{Considerações finais}

Para continuidade das nossas reflexões neste âmbito, algumas já descritas ao longo deste texto, citamos duas recomendações mencionadas por duas mulheres durante a Conferência Rio +20 :

A ONU Mulheres recomendou maior participação feminina na sociedade, indústria, comércio e, principalmente, política mundial, são essenciais para atingir o verdadeiro desenvolvimento sustentável da humanidade, o caminho até que a mulher receba a consideração almejada permanece longo. Há avanços, mas a mulher ainda está longe na maioria dos países de participar da sociedade no mesmo pé de igualdade que os homens", para haver desenvolvimento sustentável, é essencial que os governos incluam programas ativos de inclusão da mulher em todas as áreas: comercial, social, de saúde, política, educacional e nas ciências e pesquisa, entre tantas outras. (Michelle Bachelet, ONU - Mulheres, Riocentro, junho 2012).

Nos últimos anos venho estudando tudo o que se passou desde 1992 e o que me vem mais à cabeça são as meninas e mulheres, que continuam em sua maioria excluídas de participar da sociedade mundial, principalmente, é essencial que o mundo respeite o direito da muIher em determinar quantos filhos quer ter e como quer controlar o seu corpo, isso é o primeiro passo em determinar a paridade social dos gêneros. (Gro Harlem Brundtland, ex-primeira-ministra da Noruega, atual representante do secretário-geral para Mudanças Climáticas, Riocentro junho 2012).

8 Roteiros do Brasil, Ministério do Turismo, 2007. 
De acordo com essas recomendações, as autoridades mencionadas afirmam que algumas mulheres desta geração abriram frentes inusitadas no mundo da política, conquistando espaços e direitos nos países nórdicos até então considerados impossíveis, como igualdade de direitos na educação e na economia, simultaneamente ao direito universal de cuidar da família sem sofrer penalidades econômicas e profissionais.

Diante do exposto, refletimos que é, para além da discussão sobre a Câmara Legislativa do Distrito Federal, como espaço de participação, é fulcral que se tenha em mente que a opressão das mulheres não se dá somente no microespaço, ela existe também em outros domínios. É necessário construir a emancipação feminina e a luta contra a desigualdade e todas as opressões. O local das organizações populares urbanas e rurais, dos sindicatos, de outras oportunidades surgidas diante das várias questões: econômicas, políticas e sociais que se apresentam para serem transformadas em ações, intervenções e políticas voltadas para a emancipação de todos os gêneros, e proteção do planeta. Finalmente, é de grande importância para o turismo sustentável que se valorizem todos esses espaços, e consequentemente os gêneros, quanto às potencialidades existentes.

\section{Referências}

ENGELS, Friedrich. A origem da família, da Propriedade Privada e do Estado. São Paulo: Expressão popular, 2010.

IANNI, Octávio. A idéia de Brasil moderno. São Paulo: Brasiliense, 1992.

IAMAMOTO, Marilda Vilela. Mundialização do capital, "questão social" e Serviço Social. In: Revista Em Pauta, n.21, 2008.

IBGE Indicadores de Desenvolvimento Sustentável, 2012.

LOUREIRO, Isabel. Rosa Luxemburgo: Vida e obra. São Paulo: Expressão popular, 2005. MÉSZÁROS, István. A crise estrutural do capital. São Paulo: Boitempo, 2011.

MINISTÉRIO DO TURISMO. Roteiros do Brasil, Conteúdo Fundamental Turismo e Sustentabilidade, Secretaria Nacional de Políticas de Turismo, 1a Edição, 2007.

OMT. Código de Ética Mundial para o Turismo. Tradução para o português pela FUNDATEC / Câmara de Turismo do Rio Grande do Sul, 2000.

REED, Evelyn. Sexo contra sexo ou classe contra classe. São Paulo: Editor José Luís e Rosa Sundermann, 2008. 
SOUZA, B. S. Um discurso sobre as ciências. Porto: Ed. Afrontamento, 1993.

TRIGO, L. G. Turismo e civilização. São Paulo: Contexto, 2001.

\section{Sítios visitados:}

Portal da Câmara Legislativa do Distrito Federal www.cl.df.gov.br (acesso em 23/11/2012). www.economiabr.net Acessível em 20/10/;2013.

www.onu.org.br.integraçãodamulher Acessivel em 20/10/2013.

www.sustentávelturismo.com Acessível em20/10/2013.

www.suapesquisa.com/ecologia/saúde Acessível em 20/10/2013. 